\title{
Librarians as Knowledge Builders: Strategic Partnering for Service and Advocacy
}

\author{
Patricia A. Kreitz \\ Director, Technical Information Services \\ Stanford Linear Accelerator Center, Stanford University, \\ Stanford, CA 94309
}

In their article on the challenges facing the postmodern library authors Elteto and Frank warn that the "relevancy of academic libraries are at stake as a result of dramatic budget reductions and ongoing changes in the use of libraries." Recognizing the fiscal crisis facing libraries, many leaders in the profession are calling for libraries to strengthen their core roles in supporting campus research, teaching, and learning and to become more proactive and effective communicators of the critical role the library plays in supporting institutional goals.

Responding to this difficult period facing academia and interested in highlighting the creative ways academic libraries around the country are responding, ACRL President, Tyrone Cannon has chosen "Partnerships and Connections: the Learning Community as Knowledge Builders" 2 as the theme for his presidential year. His intention is to foster opportunities for libraries to "play a key role in developing, defining and enhancing learning communities central to campus life." Focusing our efforts on supporting the core business of academia will ensure that academic libraries continue to be places of "opportunity, interaction, serendipity and strong collections and remain central to the knowledge building process."

Savvy library administrators take every reasonable opportunity to communicate their library's achievements and needs to faculty and to campus administrations. They nurture academic committees and friends' groups and work strategically through campus initiatives to build support and to spread the message about the library's centrality to the academic endeavor. However articulate and persuasive library directors may be, if they are selling this 'goodness' ${ }^{3}$ by themselves, it falls flat before too long. To be successful, all such high-level efforts need to be grounded in the work of front line librarians who strategically build and consciously nurture partnerships and connections with faculty, teaching assistants, and students. Profoundly effective messages supply concrete examples of how librarians, faculty and students are actively partnering to make a difference in the work central to campus life-teaching, learning and research.

\footnotetext{
${ }^{1}$ Sharon Elteto and Donald G. Frank, "The Politics of Survival in the Postmodern Library," Portal: Libraries and the Academy 3, no. 3 (July 2003): 495.

${ }^{2}$ Tyrone H. Cannon, ALA:ACRL Website “2003-2004 President's Theme: Partnerships and Connections: The Learning Community as Knowledge Builders" at http://www.ala.org/Content/NavigationMenu/ACRL/Presidents_Page/Presidents_Page.htm, last viewed $12 / 4 / 03$.

${ }^{3}$ Concept taken from Michael Levine "Selling Goodness: the Guerilla P.R. guide to Promoting your Charity, Non-Profit Organization, or Fundraising Event" Los Angeles: Renaissance Books, 1998.
} 
For example, many librarians are partnering with faculty and students to organize instructional materials and resources for learning communities, to integrate information literacy into coursework, or to co-create digital knowledge repositories. These librarians feel a real satisfaction from their accomplishments and often receive compliments for their efforts from the faculty and students with whom they work. Those same partnerships and connections can create a secondary effect - they potentially provide the raw materials for building a cadre of faculty and student advocates who can add their perspective, and often their own voices, to help communicate the library's value. For this to happen, both administrators and front line librarians need to think about partnerships strategically and nurture them more intentionally.

One example of a knowledge building partnership that has built an enduring level of advocacy is the almost three decade collaboration begun by the Stanford Linear Accelerator Center (SLAC) and the Deutsches Elektronen-Synchrotron (DESY) libraries, and then joined by universities in Great Britain, Japan and the Former Soviet Republic, to collect, organize, and provide access to particle physics research information. The collaboration continues to grow, adding partners with new expertise or content. This partnership was initiated by the SLAC library, which is a research library serving the Stanford Linear Accelerator Center, a school of Stanford University and a national laboratory funded by the Department of Energy through Stanford University.

This knowledge building collaboration could not have lasted as long as it has, nor evolved into such a success without three key elements. First, it focuses on a core need for the faculty and researchers who use it—providing a service of continuing and evolving value. Second, from its inception, librarians worked actively to communicate upwards and outwards and to engage faculty to do the same about the value of the project. Third, librarians, faculty and institutions participating in the project continue to receive concrete benefits from their involvement in the partnership.

In 1969 and 1970, librarians at SLAC conducted extensive interviews to learn how particle physicists currently did their research, communicated with colleagues, and wrote and distributed their papers. SLAC interviewers also asked the physicists to speculate on what they wished they could do. From this data ${ }^{4}$ emerged an ideal scholarly workstation, narrower in subject content than Vannevar Bush's MEMEX ${ }^{5}$ but broader in access to tools for design, analysis, and authoring and broader in functional integration than V. Bush originally envisioned. Reaching that comprehensive, visionary goal has taken years of partnerships by librarians, physicists and their collaborating institutions.

The partnership's first goal was to quite traditional, to identify, organize and provide access to the pre-publication literature of the fields of particle and accelerator physics. Before this effort, authors shared advance paper copies of articles (called

${ }^{4}$ Louise Addis, "A Brief and Biased History of Preprint and Database Activities at the SLAC Library, 1962-1994” Menlo Park: Stanford University, 2002. URL:

http://www.slac.stanford.edu/spires/papers/history.html, last viewed 12/5/03.

${ }^{5}$ Vannevar Bush, “As We May Think”, Atlantic Monthly, July 1945. URL:

http://www.theatlantic.com/unbound/flashbks/computer/bushf.htm, last viewed 12/5/03. 
preprints) they'd submitted to journals with colleagues. Access to advance research information was often based on who knew whom. Authors at wealthier institutions were able to share their papers widely since their institutions could fund mail distribution. Physicists at SLAC and DESY worked with the librarians to publicize to their colleagues internationally SLAC's interest in receiving all preprints. SLAC then compiled the weekly acquisitions list in a print form, including author contact information so researchers could request a copy of a listed preprint, and distributed this list worldwide. This compilation was a major milestone in democratizing access to the field's literature, comparable to the technical innovations in the early 1990's of the World Wide Web's user-friendly Internet access and to the creation of the e-print archive where particle physicists could self-publish electronic full text preprints.

This list eventually became a full-fledged bibliographic database, the 'killer app' that popularized the newly-invented World Wide $\mathrm{Web}^{6}$ and the first index to list the arXiv.org e-print numbers, and then, of course to link to the full text at arXiv.org. The project continues now offering integrated access to more than a half dozen databases including abstracted research data formatted for input into design and analysis software, compilations of secondary and tertiary review literature, directories of researchers, institutions, and experiments, conferences and conference papers, streaming media, and, most recently, astroparticle physics publications and a jobs database.

The partnership was successful and continued to be supported through cycles of budget challenges by each library's or group's participating institutions not just because of its 'goodness' for the worldwide community of researchers, but also because the partners received direct, concrete value in return for their contributions. Also, the front line librarians involved assiduously communicated those benefits to practicing physicists who communicated them to the supporting universities and laboratories. One example of SLAC's benefits was that the cost of adding extra staff to receive and catalog the advance literature worldwide was offset by the advantage SLAC physicists perceived of having all the world's preprints available weekly in their local library. Comparatively expensive faculty could spend time on research and teaching rather than individually soliciting preprint copies. Staff at the DESY library contributed extensive subject headings to the list and eventually to the database. They were already cataloging the published literature of particle physics producing an annual print bibliography, the High Energy Physics Index ${ }^{7}$. In return for sharing this extensive subject indexing, they saved cataloging time by using SLAC's advanced cataloging of the preprint versions of the eventually published papers.

The librarians at each institution who work with the databases and with onsite and remote users collect unsolicited comments, most often via emails sent to the staff. They share these comments with library administrators who can use them to communicate to

\footnotetext{
${ }^{6}$ Tim Berners-Lee, Weaving the Web: The Original Design and Ultimate Destiny of the World Wide Web by its Inventor. New York: Harper, 1999. p. 46.

${ }^{7}$ Referred to as HEPI, this was the 'Readers' Guide' of particle physics until DESY ceased publication in 1994, redirecting all their print index effort to the online literature database, SPIRES-HEP, http://www.slac.stanford.edu/spires/hep/.
} 
campus administration. For the most part these comments are positive, saying things like "you have saved me many hours" or "your service is invaluable to all researchers." But front line librarians also collect and share the negative comments that are occasionally received since they not only provide opportunities for process improvements but can, in themselves, be powerful testimonials. An example was an email received last week from an angry editor who demanded "please correct your misspelling in my book title immediately-everyone is copying your mistake, as a Google search on my name will show..." Even negative comments can sometimes reveal how central a service is to a community.

The institutional commitments of our partnerships are long-standing and extremely valuable to the organizations participating. However, within the overall project to build a comprehensive, integrated knowledge environment for particle physics, individual librarians enter into more focused partnerships with faculty members. One of the most innovative examples of this is the "Top Cited HEP Articles ${ }^{8}$." The literature database tracks citations and can calculate and display the number of times an article has been cited by subsequent articles. About ten years ago, one of the library staff started compiling a list of which articles proved the most popular, i.e. most cited, in any one year. Working with the advice of one of the SLAC faculty, he accompanied the list with a couple of paragraphs clustering the articles into broad topics and restating the subjects or titles of each one that had made the cut. When the original compiler left for another position, the library asked the faculty advisor to continue the commentary if the library continued to run the analyses that produced the lists. The annotations have now become a full-fledged review of the past year's research findings and an overview of trends in the field. The annual top-cited list, and all-time top-cited compilation, along with the faculty member's review are all published on the SLAC library's website and advertised by the library on its web pages and on appropriate listservs.

The review and the accompanying compilations have become one of the most popular and eagerly awaited publications in the field. Tracking the number of hits that these articles get on the web has been a very effective metric in justifying the continued existence of even this small project. Positive email comments from researchers inquiring about the publication date of the next edition are also saved and add a human face to the web statistics.

These two examples, one of a large, multi-institutional collaboration stretching over decades, and one of a small, two-person partnership, have several lessons that can be applied to any partnership at any library. First, each of these partnerships achieves strategic goals that are of core importance to the communities and individuals they serve and to the administrations that fund them. They also matter to the librarians on the front lines who spend their time, imagination, and emotional and physical energy in the partnerships themselves - they return a high degree of satisfaction to all involved. And finally, the librarian partners make a sustained effort both to share credit and to collect

\footnotetext{
${ }^{8}$ Travis Brooks and Michael Peskin, Top Cited HEP Articles from SPIRES-HEP Database, SLAC Library, Menlo Park: Stanford University, 2002. URL: http://www.slac.stanford.edu/library/topcites/, last viewed $12 / 5 / 03$.
} 
stories or statistics — assessments both hard and 'soft' — about the value of their partnerships. Front line librarians work with their library administrations to share those stories upwards and outwards. In return, the institutions and communities supported by these partnerships reciprocate the support, even through difficult economic times.

Library directors and front line librarians need to forge their own strategic partnership if libraries are to truly respond effectively to the challenge of becoming more relevant and making that relevancy better recognized outside of the library's virtual or physical walls. Together, management and front line library staff need to identify and select those partnerships through which the library can make a real contribution to student and faculty knowledge building through concrete achievements. Our goal as librarians should be to nourish these partnerships, make certain that the outcomes are valuable to the community, and most importantly, ensure that this value is clearly and broadly communicated. In this way, academic libraries will be better positioned to meet the some of our most pressing challenges, such as declining budgets and charges of irrelevancy, because we will be active and essential partners in the core work of our academic communities-teaching, learning and research. 